\title{
Idiom Processing Abilities according to Task Types in Patients with Dementia of Alzheimer's Type
}

\author{
Seonkyoung Jeon, Jee Eun Sung \\ Department of Communication Disorders, Ewha Womans University, Seoul, Korea
}

Correspondence: Jee Eun Sung, PhD Department of Communication Disorders, Ewha Womans University, 52 Ewhayeodae-gil, Seodaemun-gu, Seoul 03760, Korea

Tel: $+82-2-3277-2208$

Fax: +82-2-3277-2122

E-mail: jeesung@ewha.ac.kr

Received: July 5, 2020

Revised: November 2, 2020

Accepted: January 19, 2021

This work was supported by the Technology Innovation Program-Industrialized Technology Innovation Project (10077553, Development of Social Robot Intelligence for Social Human- Robot Interaction of Service Robots) funded by the Ministry of Trade, Industry \& Energy (MOTIE, Korea).

\begin{abstract}
Objectives: The purpose of this study is to investigate idiom processing abilities according to task types in patients with dementia of Alzheimer's type (DAT) and healthy elderly adults. Methods: Fifteen patients with DAT and 15 elderly adults participated in this study. They took part in an idiom processing task (picture selection/oral definition) and a cognitive function test (Korean-Mini Mental State Examination [K-MMSE], Seoul Verbal Learning Test [SVLT]). The relationship between the idiom processing ability and cognitive function was examined. Multiple stepwise regression analyses were employed to explore the best cognitive function predictor of idiom processing ability in patients with DAT. Results: First, DAT patients demonstrated worse performance on idiom processing ability than healthy elderly adults in both tasks, suggesting that DAT patients interpreted the idiom more literally than healthy elderly adults. There was a significant correlation between the idiom oral definition and delayed recall scores on the SVLT and K-MMSE in the DAT group. There was a significant correlation between idiom oral definition and immediate recall scores on the SVLT in the healthy elderly adults group. Regression analyses suggested that the delayed SLVT recall scores were the most influential predictor for the idiom oral definition. Conclusion: Patients with DAT exhibited difficulties in processing idioms due to impairment in the ability to suppress literal meaning. Long-term memory appeared to be the best predictor of idiom oral performance in patients with DAT.
\end{abstract}

Keywords: Idioms, Dementia of Alzheimer's disease, Long-term memory
의학의 발달로 인해 인간의 평균 수명이 연장되면서 65 세 이상 의 노인 인구가 증가하고 있다. 우리나라는 이미 전체 인구 중에서 65세 이상의 노인 인구 비율이 급증하는 고령화 사회에 진입하였 다. 한국의 고령자 통계에 따르면 65 세 이상 인구는 738 만 1 천 명으 로 전체 인구 가운데 $14.3 \%$ 를 차지하고 있으며 2060년에는 $41.0 \%$ 의 비율로 증가할 것으로 예측된다. 노령화 지수는 2016년 100.1명 으로 2018년에는 110.5명으로 증가하는 추세이다(Statistics Korea, 2018). 이에 따라 노인에게 흔하게 나타나는 신경질환인 치매 환자 의 인구도 증가하고 있다. 2015년에 세계의 치매 인구는 약 4,680 만 으로 추정되었으며 2030년에는 약 7,470만 명, 2050년에는 1억 3,150 만 명에 도달할 것으로 예상된다. 2008년에 한국의 치매 인구는 약 42 만 명이었고, 2015년에는 약 65 만 명이 되었으며, 2050년에는 27만 명으로 증가할 것으로 예상되고 있다. 이는 전체 노인 인구의 약 $15 \%$
의 비중에 해당할 것으로 추정되는 수치이다(Korea Ministry for Health, Welfare and Family Affairs, 2019).

노인 인구에서 치매의 유병률은 점차 증가하고 있다. 치매는 지 적 능력의 손상과 더불어 인지, 운동, 정신 등 다양한 기능의 상실 을 초래하며 발병 초기 단계부터 언어 능력의 결함을 유발한다 (Ko, 2018). 이에 따라 치매와 관련하여 언어장애를 경험하는 인구 가 꾸준히 증가할 것이고 치매 환자의 언어 문제에 대한 연구의 중 요성이 높아질 것이다. 치매 환자에 대한 복지 및 재활서비스에 관 한 사회적인 요구가 커지고 있는 가운데 언어재활사의 역할과 책임 감 또한 증가한다고 볼 수 있다.

치매 유형 중에서 알츠하이머성 치매(Dementia of the Alzheimer's Type)는 전체 치매에서 가장 흔하게 나타난다. 알츠하이머성 치매는 기억력 및 인지기능의 저하가 두드러진 특징으로 알려져 있 
으나, 이러한 능력 저하는 언어 능력 손상을 야기한다(Romero \& Kurz, 1996). 이러한 언어능력 손상으로 가장 대표적인 것이 알츠 하이머성 치매 발병 초기부터 나타나는 이름대기 수행력의 저하이 다(Barr, Benedict, Tune, \& Brandt, 1992). 또한, 최근의 일을 회상 하는데 어려움을 보이기 시작하며, 이로 인해 언어를 산출하는 횟 수가 점차 감소하며 말기에 도달하게 되면 의미기억에 접근하는 것 이 제한되며, 구어 산출이 어려워진다(Patterson, Nestor, \& Rogers, 2007).

알츠하이머성 치매 환자의 언어 결함 중 어휘 산출, 이름대기와 같은 의미론적 영역의 연구는 활발히 진행되어 왔다(Bayles \& Tomoeda, 1983; Garrard, Ralph, Patterson, Pratt, \& Hodges, 2005). 알츠하이머성 치매 환자를 대상으로 한 기존의 연구는 단어 이름 대기를 중심으로 이루어졌으나 최근에는 비유적 표현, 관용구, 속 담과 같은 비문자적 언어(nonliteral language)의 손상을 다루는 연 구도 진행되고 있다(Papagno, 2001; Rapp \& Wild, 2011). 비유 언어 (figurative language)는 비문자적이고 함축적인 언어이며 은유, 관 용어, 속담 등으로 분류된다. 이를 이해하기 위해서는 함축적이고 내포적인 의미를 해석할 수 있어야 한다(Qualls \& Harris, 2003, pp. 93-94). 은유는 주제어와 매개어의 연관된 특성을 유추해내는 것이 중심이다(Larsen \& Nippold, 2007). 비유 언어 중, 속담은 짧은 구 로 구성되며 교훈이나 풍자, 비판의 의도를 보여주는 표현을 말한 다(Cho, 1988). 반면, 관용구는 단어의 문자적 의미(literal meaning)를 넘어 맥락과 화자의 의도를 고려하는 능력을 요구한다. 관 용구는 사회적 동의 하에 굳어진 동결된 구(frozen phrases)로 표현 되고, 그 의미는 새로운 심성 어휘(mental lexicon)로 규정되어, 특정 단어의 전형적이고 통상적인 의미 분석으로 해석될 수 없는 특징 을 가진다(Nunberg, Sag \& Wasow, 1994). 국어국문학사전(Seoul National University, 1973)에 따르면 관용어 또는 관용구란 광의로 는 한 언어의 체계로서 다른 언어와의 상대적인 특색에 기초한 것 이라고 하였으며 협의로는 특정한 언어 내부의 관습적인 표현 방법 만을 의미하는 것이라고 하였다. 관용구는 둘 이상의 단어가 결합 된 형식으로 표현되지만 의미적으로는 하나의 단위로 인식된다 (Moon, 2002). 따라서 관용구를 처리할 때는 문자적 해석(literal interpretation)을 억제하고, 관용적 의미로 통용되는 새로운 의미 를 활성화하는 언어 능력이 요구된다고 보고하였다(Papagno, Lucchelli, Muggia, \& Rizzo, 2003).

성인을 대상으로 한 비유 언어 처리 능력에 대한 기존의 연구는 우반구 및 좌반구 손상 환자를 중심으로 이루어졌다. 특히 비유 언 어에 해당하는 관용구의 처리는 우반구에서 이루어진다는 많은 연구가 보고되었다(Jang \& Choi, 2010; Jung, 2008; Mayer, Caruso,
\& Salovey, 1999). 그러나 관용구 처리에 좌반구가 영향을 미칠 수 있으며 전두엽의 기능에 기인한다는 연구도 보고되고 있다(Mashal, Faust, Hendler, \& Jung-Beeman, 2008; Papagno, Tabossi, Colombo, \& Zampetti, 2004; Tompkins \& Lehman, 1998). 따라서 관용구 처리는 반구 편재성이 아닌 전반적인 뇌 기능 저하와 관련될 수 있 으며 다양한 질환을 대상으로 관용구 연구가 진행될 필요가 있다. 국내에서는 경도인지장애군을 대상으로 한 속담 연구(Woo, Kim, \& Kim, 2015)와 노화에 따른 비유 언어 처리 능력 연구(Kim \& Yoon, 2016)가 있으나 신경퇴행성 질환인 치매를 대상으로 진행된 관용구 연구는 극히 제한적이다.

알츠하이머성 치매 환자의 관용구 해석에 관한 국외의 연구를 살펴보면 Kempler, Van과 Read (1988)의 연구에서 PrAD (Probable Alzheimer's Disease)는 정상 성인 집단에 비해 친숙한 관용구 해석에 어려움을 보였다는 결과가 있었다. Papagno (2001)의 연구 에서는 알츠하이머성 치매의 증상은 관용구 처리 능력에 영향을 미치지 않는다는 결과가 보고되었다. 알츠하이머성 치매 환자의 관 용구 처리 능력에 영향을 주는 요인에 대한 주장도 각 연구에 따라 차이가 있다. Papagno (2001)의 연구에서는 알츠하이머성 치매 환 자가 관용구 처리에 낮은 수행력을 보이는 것은 어휘-의미적(lexical-semantic)이고 통사론적인 능력의 결함 때문이라기보다 집행 기능(executive functions)의 손상 때문이라는 주장을 제기하였다. 이는 관용구 처리는 통사적 처리(syntactic processing)와 관련 있 다는 연구(Peterson, Burgess, Dell, \& Eberhard, 2001)와는 상이한 주장이다.

이와 같이 알츠하이머성 치매 환자의 관용구 처리 능력은 연구 에 따라 상이한 결과가 도출되고 있으며 다양한 언어권의 연구를 통해 지속적으로 논의될 필요가 있다. 한국에서 성인을 대상으로 한 관용구 연구는 정상 청년층과 노년층을 대상으로 한 Kim과 Yoon (2016)의 연구와 뇌손상 환자를 대상으로 한 연구가 있다 (Jang \& Choi, 2010; Jung, 2008). 그러나 한국에서 알츠하이머성 치 매 환자를 대상으로 한 관용구에 관한 연구는 극히 제한적이다. 알 츠하이머성 치매(Dementia of the Alzheimer's Type)는 기억력 및 인지기능의 저하가 주요 증상이며 언어를 산출하고 이해하는데 어 려움이 나타난다. 이러한 증상을 바탕으로 국내의 알츠하이머성 치매 환자도 관용구 처리 능력의 저하를 보일 수 있을 것으로 추정 할수 있다.

알츠하이머성 치매에 의한 인지적 기능 저하는 주의 및 집행기 능, 시지각, 의미기억 등의 다양한 하위 분야 손상을 야기한다(Reitz, Honig, Vonsattel, Tang, \& Mayeux, 2009). 인지기능 중에 장기 기억은 입력된 정보를 저장하고 인출할 수 있게 한다. 관용구는 어 
휘적으로 결합된 구조적 정보의 인출(retrieval)을 요구하며 이러한 정보는 장기기억 속에 저장된다고 하였다(Sprenger, Levelt, \& Kempen, 2006). 이를 통해 관용구를 처리하는 과제는 기억 속에 저장된 정보를 인출하는 과정을 요구하기 때문에 장기기억 능력과 상관성 이 있을 것이라고 예상해볼 수 있다. 따라서 본 연구에서는 친숙 (familiar)하고, 불투명(opaque)하며, 모호한(ambiguous) 관용구 를 선정하여 그림 선택하기와 설명하기 과제를 통해 알츠하이머성 치매 환자의 관용구 처리 능력을 살펴보고자 하였다. 또한 알츠하 이머성 치매에 의해 저하된 인지기능 중에서 이러한 능력을 예측할 수 있는 변수가 무엇인지 알아보고자 하였다. 이러한 인지기능 관 련 요인을 알아보기 위해 인지기능의 장애 여부를 선별하는 데 보편 적으로 쓰이는 검사도구인 간이정신상태 검사(Korean-Mini Mental State Examination, K-MMSE; Kang, 2006; Kang \& Na, 2003)와 장기기억 중, 의미기억을 살펴보는 서울언어학습검사(Seoul Verbal Learning Test, SVLT; Kang, Jahang, \& Na, 2012)의 즉각회상과 지 연회상을 실시하여 살펴보았다.

연구 질문은 아래와 같다.

첫째, 알츠하이머성 치매 환자 집단과 정상 노인 집단은 과제 제 시 유형(그림 선택하기, 설명하기)에 따른 관용구 처리 능력에 있어 서 유의한 차이를 보이는가?

둘째, 알츠하이머성 치매 환자 집단과 정상 노인 집단은 관용구 그림 선택하기 과제에서 반응 유형별 차이를 보이는가?

셋째, 알츠하이머성 치매 환자 집단과 정상 노인 집단에서 관용 구 처리 능력은 인지기능 관련 요인과 상관관계가 유의한가?

넷째, 인지기능 관련 변수 중에서 알츠하이머성 치매 환자 집단 의 관용구 처리 능력을 유의하게 예측하는 변수는 무엇인가?

\section{연구방법}

\section{연구대상}

본 연구의 대상자는 알츠하이머성 치매 환자 15 명과 정상 노인 15 명이다. 본 연구는 모든 연구 대상자에게 연구의 목적, 실험 내용 과 절차, 소요 시간 등에 대한 안내를 한 뒤 서명을 통해 동의를 받 았으며 생명윤리위원회의 승인을 받아 진행하였다(ewha-2019090009-01). 두 집단은 모두 (1) 한국어를 모국어로 사용하고, (2) 만 65 세 이상으로, (3) 자가보고에 기반하여 일상생활에서 시력과 청 력에 문제가 없는 사람으로 선정하였다.

알츠하이머성 치매 환자는 (1) National Institute of Neurological and Communicative Disorders and Stroke and the Alzheimer's Disease and Related Disorders Association (NINCDS-ADRDA;
Table 1. Demographic information on participants

\begin{tabular}{lccc}
\hline & DAT $(\mathrm{N}=15)$ & Healthy elderly (N=15) & $t$ \\
\hline Age (yr) & $81(9.72)$ & $79(6.57)$ & .506 \\
Education (yr) & $5.6(4.79)$ & $8.47(5.05)$ & -1.594 \\
\hline
\end{tabular}

Values are presented as mean (SD).

DAT = dementia of Alzheimer's type.

McKhann et al., 1984)의 진단기준을 따라 신경과 전문의로부터 알 츠하이머성 치매로 진단받은 환자로, (2) 알츠하이머성 치매 이외의 신경적, 정신과적 질환이 없고, (3) 임상치매척도(Clinical Dementia Rating Scale, CDR; Morris, 1993)에 따라 경도 치매 집단(CDR 1)에 해당하는 환자이며, (4) 간이정신상태 검사(K-MMSE; Kang, 2006; Kang \& Na, 2003) 실시 결과, 경증 치매 수준(23-17점)에 있 는 자이며, (5) 전반적 퇴화척도(Global Deterioration Scale, GDS; Reisberg, Ferris, de Leon, \& Crook, 1982)에서 5점 이하의 경중도 (mild to moderate)에 속하는 사람이다.

또한 모든 알츠하이머성 치매 환자의 인지기능을 알아보기 위해 SNSB-II의 하위 검사인 서울언어학습검사(SVLT; Kang et al., 2012) 에서 즉각회상 과제와 지연회상 과제를 실시하였다.

정상 노인은 (1) 간이정신상태 검사(K-MMSE; Kang, 2006; Kang $\& \mathrm{Na}, 2003)$ 점수가 정상범위에 해당하며, (2) 서울신경심리검사 2 판 (Seoul Neuropsychological Screening Battery, SNSB-II; Kang et al., 2012)의 하위 기억 검사(digit span-forward, digit span-backward)와 서울언어학습검사(SVLT) 결과가 연령 및 교육수준에 비 해 $16 \%$ ile 이상이며, (3) 알츠하이머성 치매 환자 집단과 비교하여 평균 연령 및 교육연수를 일치시킨 노인과, (4) 자가보고에 의한 신 경학적 소견이나 정신적 질환이 없고, (5) 이로 인한 약 복용 경험도 없는 사람이다.

두 집단의 연령과 교육연수에서 유의한 차이가 나타나는지 알아 보기 위해 집단별 독립 표본 $t$ 검정(two-independent samples $t$-test) 을 실시하였다. 그 결과 연령과 교육연수 모두에서 집단 간 차이가 통계적으로 유의미하지 않은 것으로 나타났다. 결과는 Table 1과 같다.

\section{연구과제}

\section{관용구 과제}

본 논문에서는 관용구 처리 능력을 알아보기 위하여 Jung (2008) 의 과제를 수정, 보완하여 대상자에게 사용하였다. 정상 성인 30 명 (청년층 20명, 중장년층 10 명)을 대상으로 관용어 과제 30 문항이 포함된 과제를 실시하여 오답률이 $10 \%$ 이상인 5 문항을 제외하여 
총 25 문항을 본 연구에 사용하였다. 관용구 처리 과제의 관용구 목 록은 Appendix 1에 제시하였다.

먼저, 관용구 처리 능력에 대한 과제로 문장을 듣고 그림 선택하 기(picture selection) 과제에서는 관용구 그림 검사 도구가 사용되 었다. 실험 그림은 3지선다로 구성되었고, 3 개의 그림을 세로 방향 으로 배치하였다. 그림은 선 그림(line drawing)으로 제시되었으며, 세 가지 그림은 관용구 의미(figurative meaning)의 그림(정답), (b) 문자적 의미(literal meaning)의 그림(오답), (c) 상관성이 없는 그림 (오답)의 형태로 구성하였다.

시력이 저하된 노년층의 특성을 고려하여 3지선다 전체 그림은 가로 $14 \mathrm{~cm}$, 세로 $23 \mathrm{~cm}$, 각각의 그림은 가로 $14 \mathrm{~cm}$, 세로 $5.5 \mathrm{~cm}$ 로 구성되었다. 실험 그림의 예는 Figure 1에 제시하였다.

다음으로, 친숙한 관용구 처리 능력을 한 과제 제시 방법의 하나 로서 관용구의 의미를 구어적으로 표현하는 방법인 설명하기(oral definition) 과제가 사용되었다. 관용구 처리 능력에 관한 연구는 주 로 설명하기, 그림 지적하기, 문장을 읽고 답을 고르는 방식의 다지 선다 형태의 과제가 사용된다. 보기 문항을 읽고 해당하는 뜻이라 고 생각하는 문항을 고르는 방식인 선다형 선택 과제는 글을 읽고 해석하는 문해력(literacy)이 요구된다. Choi (1990)의 연구에서 우 리나라 노인의 저학력과 문맹의 비율이 높다는 점을 고려했을 때,

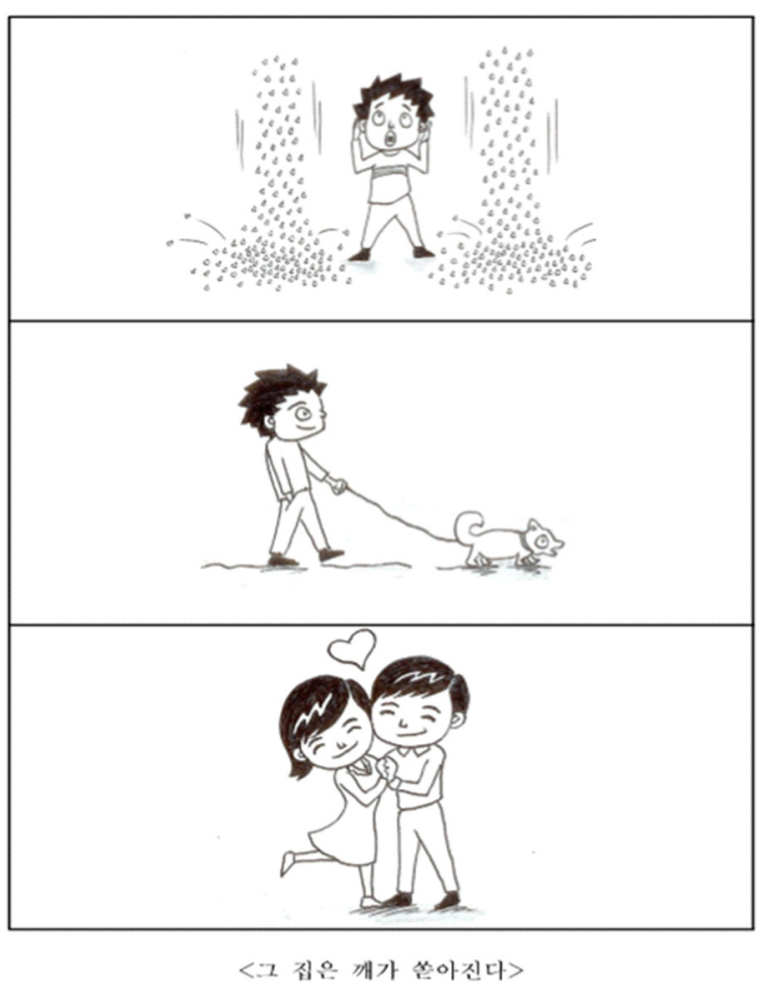

Figure 1. The example of the picture selection task (Jung, 2008, pp.93).
65세 이상의 노년층을 대상으로 하는 본 연구에 글을 읽고 판단하 는 선다형 선택 과제는 적절하지 않다고 판단하였다. 따라서 본 연 구에서는 실험자가 관용구를 청각적으로 제시하여 대상자가 인식 하는 의미를 구어로 표현하는 설명하기 과제를 통해 관용어 처리 능력을 알아보았다.

\section{인지기능 과제}

인지기능은 일상생활에서 나타나는 일들을 사고하고, 기억하며 상황을 판단하고 실행하는 과정이다. 이러한 인지기능은 지남력, 주의집중력, 기억력, 판단력, 계산 능력, 언어기능 등의 지적인 능력 을 포함한다(Korean Neuropsychiatric Assocation, 2002). 본 연구 에서는 인지기능이란 전반적 인지기능 평가인 간이정신상태 검사 (K-MMSE; Kang, 2006; Kang \& Na, 2003)와 포괄적인 인지기능을 평가하는 표준화된 검사인 신경심리검사 2판(Seoul Neuropsychological Screening Battery, SNSB-II)의 하위 검사인 서울언어학습 검사(SVLT; Kang et al., 2012)에서 즉각회상과 지연회상 과제를 통 해 측정된 점수를 의미한다.

즉각회상은 실험자가 12 개의 단어 목록을 대상자에게 불러준 다음 가능한 많은 단어를 지연시간 없이 회상하는 방식이며 3 회를 반복적으로 실시하였다. 3 회 동안 얻은 점수를 합산하여 총점을 계 산하였다. 지연회상은 12 개의 단어 목록을 20 분의 시간이 지연된 후에 기억나는 대로 회상하는 방식으로 실시되었다. Baddeley와 Warrington (1970)의 연구에서 SVLT_즉각회상은 단기기억과 장 기기억과 관련이 있으며 지연회상은 장기기억을 더 민감하게 반영 한다고 하였다. 또한 Bruno, Reiss, Petkova, Sidtis 그리고 Pomara (2013)의 연구에서 장기기억과 관련된 지연회상은 인지기능의 손 상 정도를 반영하는 것으로 보았다. 따라서 대상자가 장기기억에 저장된 정보를 인출하는 능력을 알아보기 위해 본 과제를 실시하 였다.

\section{연구절차}

본 실험의 자료 수집은 독립적이고 조용한 공간에서 실시되었다. 검사자는 검사 실시 전에 연구 과제에 대한 설명을 제공하였다. 대 상자가 검사 방법을 충분히 숙지하지 못하였으면 다시 한번 설명을 제공하였다. 검사 자극이 제시된 후 대상자가 20초 동안 반응을 보 이지 않으면 자극을 다시 제시하였다. 그림 선택하기(picture selection) 과제에서 대상자의 반응은 즉시 결과를 기록하고 설명하기 (oral definition) 과제에서 대상자의 음성은 디지털 녹음기를 통해 녹음을 하였다. 추후에 검사-재검사 신뢰도를 위해 전체 표본의 $13.33 \%$ 를 무작위로 선정하여 재평가한 결과 검사-재검사 신뢰도 
는 그림 선택하기 과제는 $100 \%$, 설명하기 과제는 $96 \%$ 로 나타났다.

\section{자료분석}

관용구 그림 선택하기

그림 선택하기 과제(picture selection)의 경우 객관적 기준에 따 라 정반응인 관용적인 의미를 선택하였을 경우 1점, 지시적 의미나 맥락과 관련이 없는 그림을 지적하였을 경우 0 점으로 계산하였다. 전체 문항의 수인 25점을 만점으로 평가한 뒤 백분율로 변환하여 계산하였다. 정답률은 대상자가 획득한 점수를 총점으로 나누고 100 을 곱하여 산출하였다.

\section{관용구 설명하기}

설명하기 과제(oral definition)는 관용구 사전에 정의된 의미를 정반응으로 채점하였다. 또한 정상 성인 30 명(청년층 10 명, 중장년 층 20 명)을 대상으로 관용구의 의미에 대해 설문조사를 실시하여 3 명 이상의 성인이 동일하게 답변한 어휘를 정반응에 해당하는 것 으로 반영하여 채점하였다. 대상자가 핵심 어휘를 포함하지 않고 설명한 경우에는 오반응으로 채점하였다. 정반응 시 1점, 오반응 시 0점으로 점수를 산정하였다.

\section{통계적 처리}

자료의 통계적 처리는 SPSS 25.0 (Statistics Package for the Social Science, version 25.0) 프로그램을 이용하였다. 먼저 알츠하이머성 치매 환자 집단과 정상 노인 집단 간 과제 유형에 따른 관용구 처리 능력에 유의한 차이가 있는지 분석하기 위하여 이원분산분석(twoway mixed ANOVA)을 실시하였다. 또한 관용구 그림 선택하기 과 제에서 알츠하이머성 치매 환자 집단과 정상 노인 집단 간 반응 중 에서 정반응-주요 오반응 비율의 차이가 통계적으로 유의한지 분 석하기 위하여 교차분석(chi-square test)을 실시하였다. 집단별 관 용구 처리 능력과 인지기능 관련 요인 간 상관관계를 알아보기 위 해 Pearson 상관계수를 산출하였다. 또한 인지기능 관련 변수 중에 서 알츠하이머 치매 집단의 관용구 처리 능력을 예측하는 변수를

Table 2. Descriptive statistics of percentage (\%) of picture pointing, oral definition scores by group

\begin{tabular}{lcc}
\hline & Picture selection & Oral definition \\
\hline DAT $(\mathrm{N}=15)$ & $35.20(14.75)$ & $37.87(11.99)$ \\
Healthy elderly $(\mathrm{N}=15)$ & $58.93(18.05)$ & $61.87(11.3)$ \\
Total $(\mathrm{N}=30)$ & $47.07(20.2)$ & $49.87(16.73)$ \\
\hline
\end{tabular}

Values are presented as mean (SD). DAT = dementia of Alzheimer's type.
알아보고자 단계적 회귀 분석(stepwise regression analysis)을 실시 하였다.

\section{연구결과}

\section{두 집단 간 관용구 처리 능력 비교}

알츠하이머성 치매 환자 집단과 정상 노인 집단의 과제 유형에 따른 관용구 처리 능력에 대한 검사 결과, 각 집단의 관용구 처리 과제 정답률에 대한 기술통계는 Table 2와 같다.

알츠하이머성 치매 환자 집단과 정상 노인 집단의 관용구 처리 과제 유형에 따라 관용구 처리 능력의 차이가 통계적으로 유의미한 지를 검증하기 위해 집단(알츠하이머성 치매 환자, 정상 노인)과 관 용구 과제의 유형(그림 선택하기, 설명하기)을 독립변수로 하고, 관 용구 처리 과제 수행력 점수를 종속 변수로 하여 이원혼합분산분 석을 실시한 결과, 관용구 처리 능력 과제 수행력에 관한 집단의 주 효과가 통계적으로 유의하였다 $\left(F_{(1,28)}=28.608, p<.001\right)$. 즉, 알츠하 이머성 치매 환자 집단의 관용구 처리 능력 과제 수행력 평균 점수 가 정상 노인 집단의 관용구 처리 능력 과제 수행력 평균 점수에 비 해 유의하게 낮은 것으로 나타났다. 다음으로, 관용구 과제 유형에 따른 주효과가 통계적으로 유의하지 않았다 $\left(F_{(1,28)}=1.082, p>.05\right)$. 알츠하이머성 치매 환자 집단과 정상 노인 집단의 관용어 처리 과 제 유형에 관한 이차상호작용은 통계적으로 유의하지 않은 것으로 나타났다 $\left(F_{(1,28)}=.961, p>.05\right)$. 집단에 따른 관용구 처리 과제 정답 률 도표는 Figure 2와같다.

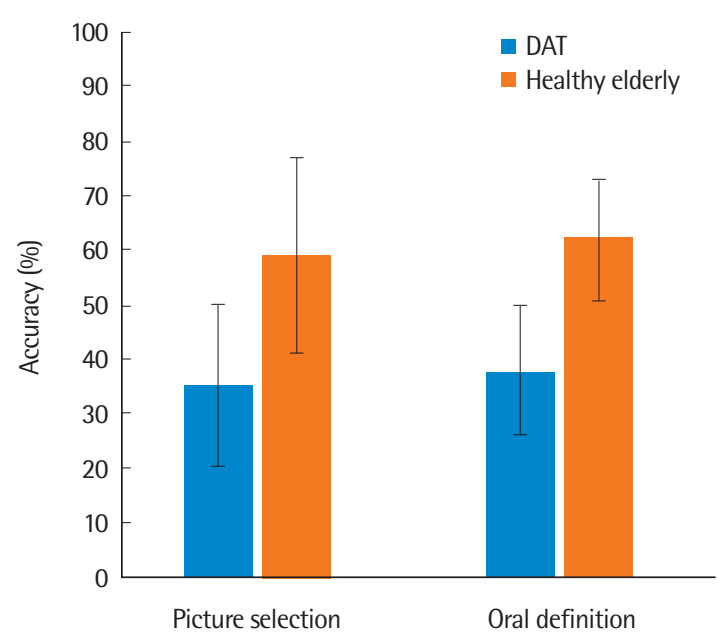

Figure 2. Accuracy (\%) of picture selection and oral definition task for both groups.

DAT = dementia of Alzheimer's type. 


\section{관용구 그림 선택하기 과제에서 집단별 반응 유형 비교} 반응 유형 분석

본 연구의 관용구 그림 선택하기 과제에서 출현할 수 있는 오반 응 유형은 관용구를 문자적 의미 그대로 해석한 오답과 전혀 관련 이 없는 오답, 무반응의 세 가지 유형이다. 관용구 처리 능력에 관한 그림 선택하기 과제에서 각 집단의 유형별 반응 비율을 Figure 3에 제시하였다.

집단별로 유형별 반응 비율을 살펴본 결과, 알츠하이머성 치매 환자 집단의 반응은 문자적 오류, 정반응, 무관련 오류, 무반응 순 으로 높은 것으로 나타났다. 정상 노인 집단의 경우 정반응, 문자적 오류, 무관련 오류, 무반응 순으로 높은 것으로 나타났다.

\section{집단에 따른 정반응-주요 오반응 비율 교차분석}

알츠하이머성 치매 환자 집단, 정상 노인 집단에 따른 정반응과 두 집단에서 오반응 유형 중 가장 높은 비율로 나타난 문자적 오류 에서 유의한 차이가 존재하는지 가설검정을 알아보기 위해 교차 분석을 실시한 결과, 두 집단에 따른 정반응과 문자적 오류에 대해 통계적으로 유의한 차이가 존재하는 것으로 나타났다 $\left(\chi^{2}=5.000\right.$, $p<.05)$. 알츠하이머성 치매 환자 집단은 정상 노인 집단에 비해 정

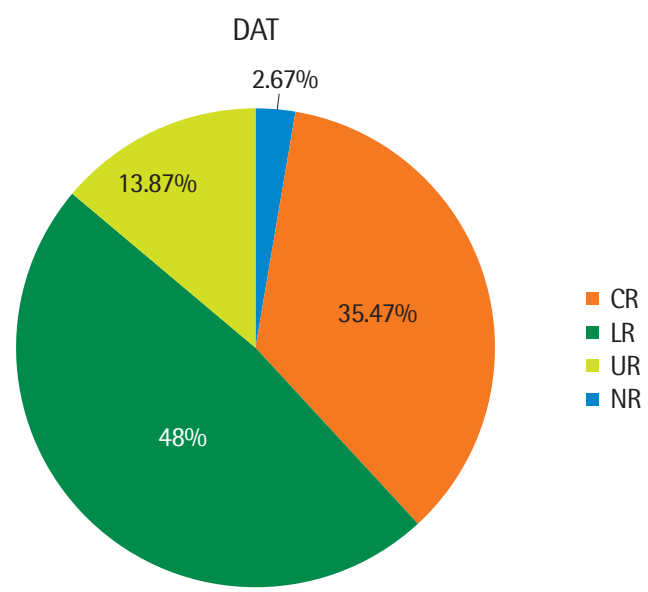

답보다 문자적 오류를 더 많이 선택했으며 정상 노인 집단은 정답 을 더 많이 선택하고 문자적 오류를 더 적은 빈도로 선택한 것을 알 수 있다. 각 집단에 따른 정반응과 오반응 유형 중 문자적 오류에 대 한 교차분석 결과는 Table 3에 제시하였다.

\section{각 집단에서 관용구 처리 능력과 인지기능 관련 요인 간 상관관계}

각 집단에 따른 관용구 처리 능력과 인지기능 관련 요인과 상관 관계를 알아보기 위해 인지기능 검사인 간이정신상태 검사 $(\mathrm{K}-$ MMSE; Kang, 2006; Kang \& Na, 2003)와 서울언어학습검사(SVLT; Kang et al., 2012)의 하위 검사인 즉각회상과 지연회상을 실시하였 다. 각 집단의 K-MMSE와 SVLT_즉각회상, SVLT_지연회상 수행 점수의 기술통계는 Table 4 에 제시하였다.

알츠하이머성 치매 환자 집단에서 관용구 처리 능력과 인지기능 관련 요인 간 상관관계

알츠하이머성 치매 환자 집단의 과제 유형에 따른 관용구 처리 능력과 인지기능 관련 요인 간 유의한 상관이 있는지 알아보기 위 해 각 변인들 간 Pearson 상관계수를 분석하였다. 그 결과를 Table

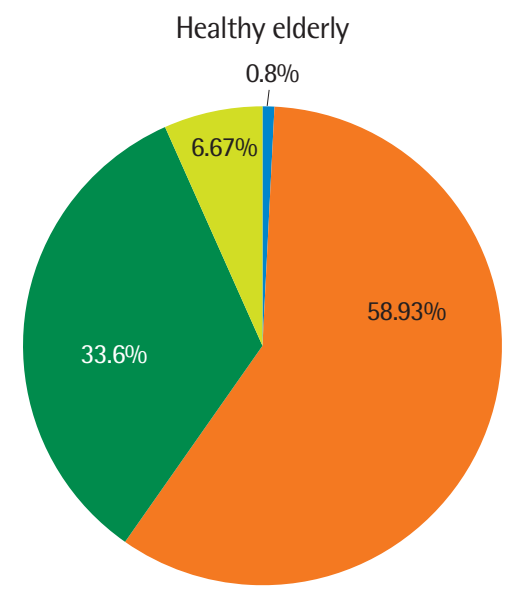

Figure 3. Percentage (\%) of responses for each group in the picture selection task. DAT = Dementia of Alzheimer's Type; $C R=$ Correct Response; $L R=$ Literal Response; UR=Unrelated Response; NR= Non-Response.

Table 3. Results of Chi-square

\begin{tabular}{|c|c|c|c|c|c|}
\hline \multirow[b]{2}{*}{ Group } & \multicolumn{2}{|c|}{ Type of response } & \multirow[b]{2}{*}{$\chi^{2}$} & \multirow[b]{2}{*}{$F$} & \multirow[b]{2}{*}{$p$-value } \\
\hline & $\begin{array}{c}\text { Correct } \\
\text { responses }\end{array}$ & $\begin{array}{l}\text { Literal } \\
\text { response }\end{array}$ & & & \\
\hline DAT (N=15) & 133 & 180 & 5.000 & 1 & .025 \\
\hline Healthy elderly $(\mathrm{N}=15)$ & 221 & 126 & & & \\
\hline Total $(\mathrm{N}=30)$ & 354 & 300 & & & \\
\hline
\end{tabular}

DAT = dementia of Alzheimer's type.
Table 4. Descriptive statistics of cognitive functions for both groups

\begin{tabular}{lrc}
\hline & DAT $(\mathrm{N}=15)$ & Healthy elderly $(\mathrm{N}=15)$ \\
\hline K-MMSE & $19.47(3.16)$ & $25.13(2.29)$ \\
SVLT_immediate recalls & $8.6(3.96)$ & $15(2.85)$ \\
SVLT_delayed recalls & $1.07(1.91)$ & $3.2(2.51)$
\end{tabular}

Values are presented as mean (SD).

DAT = dementia of Alzheimer's type; K-MMSE = Korean version of Mini-Mental State Examination (Kang, 2006); SVLT = Seoul Verbal Learning Test (Kang et al., 2012). 
Table 5. The correlation coefficients among the idiom processing abilities and cognitive functions variables in DAT

\begin{tabular}{lccccc}
\hline $\begin{array}{l}\text { Cognitive function } \\
\text { variables }\end{array}$ & K-MMSE & $\begin{array}{c}\text { SVLT_im- } \\
\text { mediate } \\
\text { recalls }\end{array}$ & $\begin{array}{c}\text { SVLT_de- } \\
\text { layed } \\
\text { recalls }\end{array}$ & $\begin{array}{c}\text { Oral } \\
\text { definition }\end{array}$ & $\begin{array}{c}\text { Picture } \\
\text { selection }\end{array}$ \\
\hline K-MMSE & 1 & & & & \\
SVLT_immediate recalls & .210 & 1 & & & \\
SVLT_delayed recalls & $.547^{*}$ & .301 & 1 & & \\
Oral definition & $.553^{*}$ & .209 & $.563^{*}$ & 1 & \\
Picture selection & .231 & -.088 & -.024 & .382 & 1 \\
\hline
\end{tabular}

DAT = dementia of Alzheimer's type; K-MMSE = Korean version of Mini-Mental State Examination (Kang, 2006); SVLT = Seoul Verbal Learning Test (Kang et al., 2012). ${ }^{*} p<.05$.

Table 6. The correlation coefficients among the idiom processing abilities and cognitive functions variables in healthy elderly

\begin{tabular}{lccccc}
\hline $\begin{array}{l}\text { Cognitive function } \\
\text { variables }\end{array}$ & K-MMSEE & $\begin{array}{c}\text { SVLT_im- SVLT_de- } \\
\text { mediate } \\
\text { recalls }\end{array}$ & $\begin{array}{c}\text { Oral } \\
\text { layed } \\
\text { recalls }\end{array}$ & $\begin{array}{c}\text { Picture } \\
\text { definition }\end{array}$ & selection \\
\hline K-MMSE & 1 & & & & \\
SVLT_immediate recalls & $.610^{*}$ & 1 & & & \\
SVLT_delayed recalls & $.173^{*}$ & $.621^{*}$ & 1 & & \\
Oral definition & .346 & $.536^{*}$ & .321 & 1 & \\
Picture selection & .313 & .140 & .072 & $.582^{*}$ & 1 \\
\hline
\end{tabular}

DAT = dementia of Alzheimer's type; K-MMSE = Korean version of Mini-Mental State Examination (Kang, 2006); SVLT = Seoul Verbal Learning Test (Kang et al., 2012). ${ }^{*} p<.05$.

\section{5에 제시하였다.}

알츠하이머성 치매 환자 집단에서 관용구 설명하기 과제 수행력 에서 SVLT_지연회상 $(r=.563, p<.05)$, K-MMSE $(r=.553, p<.05)$ 와 유의한 정적 상관관계가 나타났다.

\section{정상 노인 집단에서 관용구 처리 능력과 인지기능 관련 요인 간 상관관계}

정상 노인 집단의 과제 유형에 따른 관용구 처리 능력과 인지기 능 관련 요인 간 유의한 상관이 있는지 알아보기 위해 각 변인들 간 Pearson 상관계수를 분석하였다. 그 결과를 Table 6에 제시하였다.

정상 노인 집단에서 관용구 설명하기 과제 수행력에서 SVLT_즉 각회상 $(r=.536, p<.05)$ 과 유의한 상관관계가 나타났으며, 관용구 그림 선택하기 과제 $(r=.582, p<.05)$ 와 유의한 상관관계가 나타났 다. 그 외에 SVLT_즉각회상은 K-MMSE $(r=.610, p<.05)$, SVLT_ 지연회상 $(r=.621, p<.05)$ 과 유의한 정적 상관관계가 나타났다.

\section{알츠하이머성 치매 환자 집단에서 관용구 처리 능력 예측 요인}

알츠하이머성 치매 환자 집단의 관용구 처리 능력을 가장 잘 예
Table 7. Results of stepwise regression predicting idiom oral definition task in DAT

\begin{tabular}{lccccc}
\hline Predictor & B & SE & $\beta$ & $t$ & $p$-value \\
\hline SVLT_delayed recalls & 6.952 & 0.978 & .563 & 7.111 & $.029 *$ \\
\hline DAT = dementia of Alzheimer's type; SVLT=Seoul Verbal Learning Test & (Kang et al., \\
2012). \\
Dependent variable: Oral definition. \\
${ }^{*} p<.05$.
\end{tabular}

측해 주는 인지기능 관련 변수를 알아보기 위해 관용구 처리 과제 (그림 선택하기, 설명하기)를 종속변수로, 인지기능 관련 요인인 KMMSE, SVLT_즉각회상, SVLT_지연회상 3가지를 독립변수로 하 여 단계적 중다회귀분석(stepwise regression analysis)을 실시하였 다. 그 결과는 Table 7과 같다.

인지기능 관련 변수 중 관용구 처리 과제 중 하나인 설명하기 점 수를 가장 잘 예측하는 변수는 SVLT_지연회상 수행력으로 나타 났다 $\left(F_{(1,13)}=6.024, \mathrm{R}^{2}=.317, p<.05\right)$. 즉, SVLT_지연회상 과제에서 관용구 설명하기 과제 수행력을 약 $31.7 \%$ 예측하는 것으로 나타났 다. 반면 관용구 그림 선택하기 과제를 통계적으로 유의하게 예측 해주는 변수는 나타나지 않았다( $p>.05)$.

\section{논의 및 결론}

본 연구는 알츠하이머성 치매 환자 집단과 정상 노인 집단을 대 상으로 과제 유형에 따른 관용구 처리 능력을 알아보고 관용구 그 림 선택하기 과제에서 집단에 따른 반응 유형별 차이가 나타나는 지 알아보았다. 또한 두 집단에서 관용구 처리 능력은 인지기능 관 련 요인과 상관관계가 유의한지 알아보고 알츠하이머성 치매 환자 집단의 관용구 처리 능력을 유의하게 예측하는 변수를 알아보았다. 알츠하이머성 치매 환자 집단과 정상 노인 집단 간 과제 유형에 따른 관용구 처리 능력에 유의한 차이가 있는지 알아본 결과 집단 에서의 주효과가 통계적으로 유의하였다. 과제의 유형에 상관없이 알츠하이머성 치매 환자 집단은 정상 노인 집단에 비해 관용구 처 리 능력에서 저하된 수행력이 나타났다. 이는 관용구 처리 능력의 결함이 정상 노인과 구분되는 알츠하이머성 치매 환자의 특성이라 는 선행연구와 일치하는 결과이다(Rapp \& Wild, 2011). Kempler 외(1988)의 연구결과에 따르면 알츠하이머성 치매 환자는 친숙한 관용구가 제시되었을 때 단일 어휘를 바탕으로 해석하는 경향이 있는 것으로 보고된다. 즉, 알츠하이머성 치매 환자는 친숙한 관용 구를 처리할 때 관용적 의미를 우세적으로 처리하기보다 관용구에 포함된 단일 어휘의 문자적 의미에 의존하기 때문에 정상 노인 집 단에 비해 관용구 처리 능력의 저하가 두드러지게 나타나는 것으 
로 사료된다. 과제 유형에 대한 주효과는 통계적으로 유의하지 않 았다. 두 집단 모두 그림 선택하기 과제보다 설명하기 과제에서 정 답률이 높았으나 통계적으로 유의한 차이는 나타나지 않았다. 알츠 하이머성 치매 환자 집단과 정상 노인 집단의 관용어 처리 과제 유 형에 관한 이차상호작용은 통계적으로 유의하지 않은 것으로 나타 났다. 따라서 관용구 그림 선택하기 수행 능력과 관용구 설명하기 수행 능력의 차이가 정상 노인 집단에 비해 알츠하이머성 치매 환 자 집단이 유의하게 더 크게 나타나지 않았다는 것을 알 수 있다. 본 연구의 결과를 바탕으로 알츠하이머성 치매 환자 집단이 정상 노인 집단에 비해 관용구 처리 능력이 낮은 것으로 나타난 것을 알 수 있다.

본 연구의 관용구 그림 선택하기 과제에서 전체 반응 중에서 정 상 노인 집단은 정답을 선택한 비율이 가장 높았으며, 알츠하이머 성 치매 환자 집단은 정답보다 문자적 오류를 선택한 비율이 가장 높은 것으로 나타났다. 정반응과 두 집단에서 가장 높은 비율로 나 타난 오반응 유형인 문자적 오류의 비율이 각 집단별로 유의한 차 이를 보이는지 알아본 결과, 알츠하이머성 치매 환자 집단은 정상 노인 집단에 비해 유의하게 높은 문자적 오류 비율을 나타내었다. 이는 알츠하이머성 치매 환자는 관용구를 해석할 때 관용적 의미 보다 문자 그대로의 의미로 해석하는 오류를 보이는 경향이 있다 는 여러 선행연구(Kempler et al., 1988; Papagno, 2001)와 일치한다. 관용구는 문자 그대로 해석해서는 그 의미를 파악할 수 없기 때문 에 목표 자극인 관용적 의미를 이해하기 위해 간섭 자극인 문자적 의미를 배제하는 기능이 요구된다고 볼 수 있다. Barkley와 Lombroso (2000)의 연구에서 전두엽의 기능 가운데 집행기능은 관용 적 의미를 활성화시키기 위해 지시적 의미를 억제 조절(inhibition) 하는 역할을 담당한다고 설명하였다. 즉, 집행기능은 관용적 의미 를 추론하는 상위 인지 처리 과정을 담당한다는 것을 알 수 있다. Baddeley (1998)의 연구에서 알츠하이머성 치매 집단의 경우 집행 기능에 손상이 있는 것으로 보고된다. 따라서 알츠하이머성 치매 환자 집단이 높은 문자적 오류 비율을 보인 것은 집행기능의 손상 으로 관용구를 처리하는 과정에서 지시적 의미를 효과적으로 억 제하지 못하여 관용적 의미를 활성화하는데 어려움을 나타내기 때문인 것으로 사료된다.

알츠하이머성 치매 환자 집단에서 관용구 처리 능력과 상관관계 가 있는 요인을 알아보기 위해 인지기능 관련 요인과의 상관을 분 석하였을 때, 알츠하이머성 치매 환자 집단은 SVLT_지연회상과 K$\mathrm{MMSE}$ 에서 관용구 설명하기와 유의한 정적 상관을 보였다. 관용 구의 의미를 설명하기 위해서는 기억 속에 저장되어있는 관용구를 회상하고 인출하는 과정을 거치기 때문에 SVLT_지연회상과 상관
성이 나타난 것으로 사료된다. Romero와 Kurz (1996)에서 알츠하 이머성 치매 환자의 기억력 결함은 언어 능력의 수행력의 저하와 연 계된다는 결과와 같은 맥락으로 볼 수 있다. 한편, 알츠하이머성 치 매 환자 집단에서 일정한지연의 시간이 없이 회상하는 능력인 SVLT 즉각회상은 관용구 설명하기와 유의한 상관관계가 나타나지 않았 다. Warrington (1970)의 연구에서 SVLT_즉각회상은 단기기억과 장기기억과 관련이 있으며 지연회상은 장기기억을 더 민감하게 반 영한다는 점을 고려했을 때, 관용구 설명하기가 즉각적인 회상을 필요로 하기보다 장기기억의 회상을 요구하는 능력과 더 밀접한 관 련성이 있는 것으로 해석할 수 있다. 관용구는 어휘적으로 결합된 구조적 정보의 인출(retrieval)을 요구하며 이러한 정보는 장기기억 속에 저장되어 있는 것이라는 Sprenger 등(2006)의 연구와 같은 맥 락에 해당한다. 알츠하이머성 치매 환자의 관용구 설명하기 능력은 K-MMSE 수행력과 유의한 상관관계가 있는 것으로 나타났다. 인 지기능이 높을수록 관용구의 의미를 잘 이해하고 설명할 수 있다 고 해석할 수 있다. 이는 알츠하이머성 치매 환자의 문장과 구를 이 해하는 언어 능력은 작업기억, 집행기능 등의 인지 능력과 관련 있 는 것으로 나타난 Kempler 등(1988)의 선행연구와 일치한다. 정상 노인 집단에서는 관용구 설명하기가 SVLT_즉각회상 능력과 유의 한 정적 상관관계를 보였다. 또한 SVLT_즉각회상은 K-MMSE와 유의한 정적 상관관계가 나타났다. 즉, 언어적 기억력과 관용구 설 명하기 수행력은 상관이 있는 것으로 나타났다. 노년층은 기억의 용량과 인지적 자원을 효율적으로 처리하는 능력이 변화되기 때문 에 전반적인 인지기능이 감퇴하여 비유적 언어의 해석에서 어려움 이 심화된다는 Qualls와 Harris (2003)의 연구결과와 일치한다. 본 연구결과는 언어적 기억력이 관용구 설명하기 능력을 살펴보는 요 인이 될 수 있다는 점을 시사한다.

인지기능 관련 변수 중에서 관용구 그림 선택하기를 예측하는 변수는 나타나지 않았으며, 관용구 설명하기를 가장 잘 예측하는 변수는 SVLT_지연회상으로 나타났다. 즉, 지연회상 능력이 관용 구 설명하기를 약 $31.7 \%$ 로 예측하는 것으로 나타났다. SVLT_지연 회상은 관용구 설명하기와 상관관계가 높게 나타났다. 이러한 결과 가 예측 변수에 작용한 것으로 해석할 수 있다. Bruno 등(2013)의 연구에서 지연회상은 즉각회상에 비해 인지기능의 정도를 밀접하 게 나타내는 지표라고 설명하였다. 또한 지연회상은 장기기억(longterm memory)과 관련된 것으로 알려진다(Baddeley \& Warrington, 1970). Hodges, Salmon과 Butters (1990)의 연구에서 장기기억에서 의식적으로 접근하며 인식할 수 있는 외현기억(explicit memory) 은 의미기억(semantic memory)과 일화기억(episodic memory)으 로 분류된다고 보았다. 일화기억은 자신의 경험에 대한 기억이며 의 
미기억은 동질성을 지닌 문화권 사회구성원들 간에 합의가 이루어 진 세상에 대한 지식을 뜻하는 것이다(Tulving \& Bower, 1974). 관 용구는 같은 문화권의 구성원에게 통용되는 언어로 반복적으로 사용되고 일반 지식으로 축적되기 때문에 의미기억과 밀접한 관련 이 있는 것으로 해석할 수 있다. 관용구는 장기적인 의미기억 속에 저장된 관습화된 일련의 단어들이라고 보는 연구도 이를 뒷받침한 다(Burgess \& Shallice, 1997). 관용적 표현은 특정 맥락과 의미기억 에서 접근할 수 있다(Glucksberg, Brown, \& McGlone, 1993)는 선 행연구도 이와 같은 맥락에 해당한다. 따라서 관용구 설명하기는 의미기억을 반영하는 과제로 장기기억과 관련된 처리 과정을 요구 하기 때문에 지연회상과 높은 상관성을 나타내고 예측 변수로 작 용하였을 것으로 사료된다.

관용구 그림 선택하기 과제를 예측하는 변수는 나타나지 않은 것은 알츠하이머성 치매 환자 집단의 변이성을 감소시켜 낮은 상관 관계가 나타난 결과가 회귀분석에 반영된 것으로 볼 수 있다. Papagno 외(2003)의 연구에서 알츠하이머성 치매 환자가 문장-그림 연 결하기 과제에서 오류를 나타냈으나 설명하기 과제를 수행할 수 있 었던 결과는 비유적 의미에 대한 기억이 보존되나 문자적 의미를 억제하는 능력이 활성화되지 못하기 때문인 것으로 보았다. 본 연 구에서도 알츠하이머성 치매 환자가 관용구의 의미를 이해하더라 도 그림 선택하기 과제에서 문자적 의미를 억제하여 적절한 맥락을 이해하는데 어려움을 보였다고 예상할 수 있다. 따라서 그림 선택 하기 과제는 관용구가 지닌 의미를 명확하게 표출하는 정도가 상 대적으로 낮기 때문에 설명하기 과제에 비해 알츠하이머성 치매 환 자의 의미처리 능력을 민감하게 반영하지 못했을 것으로 해석할 수 있다. 본 연구에서는 지연회상이 관용구 처리 과제 중 설명하기 능 력을 예측하는 변수라는 결과가 도출되었다. 따라서 관용구 설명 하기 과제는 알츠하이머성 치매 환자를 변별하고 장기기억을 측정 하는 도구로 활용될 수 있을 것이라는 가능성을 시사한다. 인지기 능은 신경학적 질환인 알츠하이머성 치매와 그 진전 정도를 예측 할 수 있는 지표가 될 수 있다는 연구결과를 반영했을 때(Gomez \& White, 2006), 지연회상 외에도 관용구 처리 능력을 예측할 수 있 는 다양한 변수에 대한 지속적인 연구가 이루어져야 할 것이다.

그러나 본 연구의 제한점은 다음과 같다. 첫째, 본 연구에서는 알 츠하이머성 치매 환자 15 명과 정상 노인 15 명으로, 적은 수의 연구 대상자이므로 표본이 충분하지 않다. 따라서 연구결과를 알츠하이 머성 치매 집단의 전체를 대상으로 일반화하기에는 제한점이 있으 며 후속 연구에서는 집단별로 연구 대상자의 수를 충분히 확보할 필요가 있다. 둘째, 다양한 유형의 관용구를 선정할 필요가 있다. 본 연구에서는 친숙하고, 불투명하고, 모호한 관용구로 범위를 제
한하여 연구결과를 도출하였다. 후속 연구에서는 관용구의 친숙 도, 투명도가 각기 다른 다양한 특성을 지닌 관용구를 선정하여 연 구를 진행한다면 관용구의 특성에 따른 각 집단의 관용구 처리 능 력을 알아볼 수 있을 것이다. 셋째, 연구 대상자를 선정하는 단계에 서 작업기억, 집행기능 등 다양한 언어, 인지기능을 측정하는 신경 심리학적 평가를 실시했다면 대상자의 관용구 처리 능력의 결함에 영향을 미치는 요인과 원인에 대해 구체적으로 분석할 수 있었을 것이다.

\section{REFERENCES}

Baddeley, A. (1998). The central executive: a concept and some misconceptions. Journal of the International Neuropsychological Society, 4(5), 523-526.

Baddeley, A. D., \& Warrington, E. K. (1970). Amnesia and the distinction between long-and short-term memory. Journal of Verbal Learning and Verbal Behavior, 9(2), 176-189.

Bayles, K. A., \& Tomoeda, C. K. (1983). Confrontation naming impairment in dementia. Brain and Language, 19(1), 98-114.

Barkley, R. A., \& Lombroso, P. J. (2000). Genetics of childhood disorders: XVII. ADHD, Part 1: the executive functions and ADHD. Journal of the American Academy of Child \& Adolescent Psychiatry, 39(8), 1064-1068.

Barr, A., Benedict, R., Tune, L., \& Brandt, J. (1992). Neuropsychological differentiation of Alzheimer's disease from vascular dementia. International Journal of Geriatric Psychiatry, 7(9), 621-627.

Burgess, P. W., \& Shallice, T. (1997). The relationship between prospective and retrospective memory: Neuropsychological evidence. In M. A. Conway (Ed.), Cognitive models of memory (pp. 247-272). Cambridge, MA: MIT Press.

Bruno, D., Reiss, P. T., Petkova, E., Sidtis, J. J., \& Pomara, N. (2013). Decreased recall of primary words predicts cognitive decline. Archives of Clinical Neuropsychology, 28(2), 95-103.

Cho, J. (1988). A study on the grammar structure of Korean proverbs (Master's thesis). Korea University, Seoul, Korea.

Choi, W. S. (1990). The status and education of literacy in Korea (RR90). [KEDI] Research Report. 1-229.

Garrard, P., Ralph, M. A. L., Patterson, K., Pratt, K. H., \& Hodges, J. R. (2005). Semantic feature knowledge and picture naming in dementia of Alzheimer's type: a new approach. Brain and Language, 93(1), 79-94.

Glucksberg, S., Brown, M., \& McGlone, M. S. (1993). Conceptual metaphors are not automatically accessed during idiom comprehension. Memory \& Cognition, 21(5), 711-719. 
Gomez, R. G., \& White, D. A. (2006). Using verbal fluency to detect very mild dementia of the Alzheimer type. Archives of Clinical Neuropsychology, 21(8), 771-775.

Hodges, J. R., Salmon, D. P., \& Butters, N. (1990). Differential impairment of semantic and episodic memory in Alzheimer's and Huntington's diseases: a controlled prospective study. Journal of Neurology, Neurosurgery \& Psychiatry, 53(12), 1089-1095.

Jang, H., \& Choi, H. (2010). Comprehension of indirect speech acts in patients with right brain damage. Korean Journal of Communication Disorders, 15(4), 581-591.

Jung, S. (2008). The Idiom Comprehension of the Patients with Brain Damage (Master's thesis). Ewha University, Seoul, Korea.

Kang, Y. (2006). A normative study of the Korean-Mini Mental State Examination (K-MMSE) in the elderly. Korean Journal of Psychology: General, 25(2), 1-12.

Kang, Y., \& Na, D. L. (2003). Seoul Neuropsychological Screening Battery. Seoul: Human Brain Research \& Consulting Co.

Kang, Y., \& Na, D. L. (2012). Seoul Neuropsychological Screening Battery. 2nd ed. (SNSB-II). Seoul: Human Brain Research \& Consulting Co.

Kempler, D., Van, D. L., \& Read, S. (1988). Proverb and idiom comprehension in Alzheimer disease. Alzheimer Disease and Associated Disorders, 2(1), 38-49.

Kim, J., \& Yoon J., (2016). Comprehension of figurative language in young and old adults: the role of simile, metaphor, idiom and proverb. Journal of the Korean Gerontological Society, 36(4), 981-1001.

Ko, E. (2018). A study on pragmatic competence in dementia patients with Alzheimer's disease. The Korean Society of Education for Hearing-Language Impairments, 9(1), 63-78.

Korea Ministry for Health, Welfare and Family Affairs. (2019). National responsibility for dementia care. Seoul: Author.

Korean Neuropsychiatric Assocation. (2002). Dementia. Seoul: Chosunilbosa Publishing.

Larsen, J. A., \& Nippold, M. A. (2007). Morphological analysis in school-age children: dynamic assessment of a word learning strategy. Language, Speech and Hearing Services in Schools, 38(3), 201-212.

Mashal, N., Faust, M., Hendler, T., \& Jung-Beeman, M. (2008). Hemispheric differences in processing the literal interpretation of idioms: Converging evidence from behavioral and fMRI studies. Cortex, 44(7), 848-860.

Mayer, J. D., Caruso, D. R., \& Salovey, P. (1999). Emotional intelligence meets traditional standards for an intelligence. Intelligence, 27(4), 267-298.
McKhann, G., Drachman, D., Folstein, M., Katzman, R., Price, D., \& Stadlan, E. M. (1984). Clinical diagnosis of Alzheimer's disease: report of the NINCDS-ADRDA Work Group under the auspices of Department of Health and Human Services Task Force on Alzheimer's Disease. Neurology, 34(7), 939-944.

Moon, K. (2002). A study on the Korean vocabulary education by the collocation. The Society of Korean Language Education, 109(0), 217-250.

Morris, J. C. (1993). The Clinical Dementia Rating (CDR): current version and scoring rules. Neurology, 43, 2412-2414.

Nunberg, G., Sag, I. A., \& Wasow, T. (1994). Idioms. Language, 70(3), 491538.

Papagno, C. (2001). Comprehension of metaphors and idioms in patients with Alzheimer's disease: a longitudinal study. Brain, 124(7), 1450-1460.

Papagno, C., Lucchelli, F., Muggia, S., \& Rizzo, S. (2003). Idiom comprehension in Alzheimer's disease: the role of the central executive. Brain, 126(11), 2419-2430.

Papagno, C., Tabossi, P., Colombo, M. R., \& Zampetti, P. (2004). Idiom comprehension in aphasic patients. Brain and Language, 89(1), 226-234.

Patterson, K., Nestor, P. J., \& Rogers, T. T. (2007). Where do you know what you know? The representation of semantic knowledge in the human brain. Nature Reviews Neuroscience, 8(12), 976-987.

Peterson, R. R., Burgess, C., Dell, G. S., \& Eberhard, K. M. (2001). Dissociation between syntactic and semantic processing during idiom comprehension. Journal of Experimental Psychology: Learning, Memory, and Cognition, 27(5), 1223-1237.

Qualls, C. D., \& Harris, J. L. (2003). Age, working memory, figurative language type, and reading ability. American Journal of Speech-Language Pathology. 12(1), 92-102.

Rapp, A. M., \& Wild, B. (2011). Nonliteral language in Alzheimer dementia: a review. Journal of the International Neuropsychological Society, 17(2), 207218.

Reisberg, B., Ferris, S. H., de Leon, M. J., \& Crook, T. (1982). The Global Deterioration Scale for assessment of primary degenerative dementia. American Journal of Psychiatry, 139(9), 1136-1139.

Reitz, C., Honig, L., Vonsattel, J. P., Tang, M. X., \& Mayeux, R. (2009). Memory performance is related to amyloid and tau pathology in the hippocampus. Journal of Neurology, Neurosurgery \& Psychiatry, 80(7), 715-721.

Romero, B., \& Kurz, A. (1996). Deterioration of spontaneous speech in AD patients during a 1-year follow-up: homogeneity of profiles and factors associated with progression. Dementia and Geriatric Cognitive Disorders, 
$7(1), 35-40$.

Seoul National University. (1973). A dictionary of the Korean language. Center for east Asian studies. Seoul: Shingu Moonhwasa Publishing.

Sprenger, S. A., Levelt, W. J., \& Kempen, G. (2006). Lexical access during the production of idiomatic phrases. Journal of Memory and Language, 54(2), 161-184.

Statistics Korea. (2018). Statistics of the elderly. Daejeon: Author.

Tompkins, C. A., \& Lehman, M. T. (1998). Interpreting intended meanings after right hemisphere brain damage: an analysis of evidence, potential accounts, and clinical implications. Topics in Stroke Rehabilitation, 5(1), 2947.

Tulving, E., \& Bower, G. H. (1974). The logic of memory representations. Psychology of Learning and Motivation, 8, 265-301.

Woo, H., \& Kim, H., \& Kim, J. (2015). The utility of proverb interpretation task as a marker of cognitive impairment in mild cognitive impairments. The Korean Gerontological Society, 35(3), 785-796. 
Appendix 1. 관용구 처리 과제의 관용구 목록

\begin{tabular}{|c|c|c|c|c|}
\hline & 관용구 & 실험문장 & 어절 & 음소갯수 \\
\hline 1 & 지도 그리다 & 수박 먹고 지도 그렸다. & 4 & 9 \\
\hline 2 & 꼬리표 붙다 & 그 일로 꼬리표가 붙었다. & 4 & 10 \\
\hline 3 & 나사 빠지다 & 어딘지 모르게 나사 빠진 것 같다. & 6 & 13 \\
\hline 4 & 목 마르다 & 열정에 목이 마르다. & 3 & 8 \\
\hline 5 & 미역국 먹다 & 이번 일에 미역국 먹었다. & 4 & 10 \\
\hline 6 & 바가지 쓰다 & 그 사람한테 바가지 썼다. & 4 & 10 \\
\hline 7 & 싹이 노랗다 & 어린 것이 싹이 노랗다. & 4 & 9 \\
\hline 8 & 머리 쓰다 & 일을 해결하기 위해 머리를 썼다. & 5 & 13 \\
\hline 9 & 죽 쑤다 & 이번 일에 죽을 쒔다. & 4 & 8 \\
\hline 10 & 못 박다 & 그 말이 내 가슴에 못을 박았다. & 6 & 12 \\
\hline 11 & 간이 부었다 & 어린 녀석이 간이 부었다. & 4 & 10 \\
\hline 12 & 찬 물 끼얹다 & 전체 분위기에 찬 물을 끼얹었다. & 5 & 13 \\
\hline 13 & 국물도 없다 & 너한테는 국물도 없다. & 3 & 9 \\
\hline 14 & 깨가 쏟아지다 & 그 집은 깨가 쏟아진다. & 4 & 9 \\
\hline 15 & 뚜껑 열리다 & 그 소식을 듣고 뚜껑이 열렸다. & 5 & 12 \\
\hline 16 & 빛을 보다 & 오랜 노력이 드디어 빛을 보았다. & 5 & 13 \\
\hline 17 & 손이 크다 & 일 장만에 손이 크다. & 4 & 8 \\
\hline 18 & 녹슬다 & 실력이 녹이 슬었다. & 3 & 8 \\
\hline 19 & 매듭짓다 & 일을 매듭지었다. & 2 & 7 \\
\hline 20 & 가방 끈이 짧다 & 옛날 사람이라 가방 끈이 짧다. & 5 & 12 \\
\hline 21 & 돈을 굴리다 & 열심히 돈을 굴렸다. & 3 & 8 \\
\hline 22 & 마른침을 삼키다 & 숨죽이고 마른침을 삼켰다. & 3 & 11 \\
\hline 23 & 거미줄 치다 & 목구멍에 거미줄 치게 생겼다. & 4 & 12 \\
\hline 24 & 비행기 태우다 & 잘 보이려고 열심히 비행기 태웠다. & 5 & 14 \\
\hline 25 & 숟가락을 놓다 & 시름시름 않다 숟가락을 놓았다. & 4 & 13 \\
\hline
\end{tabular}

Jung(2008)에서 수정 발췌함. 


\title{
국문초록
}

\author{
알츠하이머성 치매 환자의 과제 유형에 따른 관용구 처리 능력 비교 \\ 전선경 · 성지은 \\ 이화여자대학교 언어병리학과
}

배경 및 목적: 본 연구에서는 알츠하이머성 치매 환자의 과제 유형에 따른 관용구 처리 능력을 알아보고자 한다. 방법: 본 연구는 15 명 의 알츠하이머성 치매 환자와 연령과 교육연수를 일치시킨 정상 노인 15 명을 대상으로 하였다. 관용구 처리 능력은 그림 선택하기와 설 명하기 과제를 사용하였으며, 인지기능은 간이정신상태검사(K-MMSE)와 서울언어학습검사(SVLT)를 사용하여 평가하였다. 관용구 처리 능력과 인지기능 관련 요인의 상관성을 살펴보고 다중회귀분석을 통해 알츠하이머성 치매 환자의 관용구 처리 능력을 가장 잘 예 측할 수 있는 변수를 알아보았다. 결과: 과제 유형에 따른 관용구 처리 능력은 알츠하이머성 치매 환자 집단이 정상 노인 집단보다 유의 하게 낮았다. 알츠하이머성 치매 환자 집단은 관용구를 처리할 때 문자적으로 해석하는 경향이 있었다. 알츠하이머성 치매 환자 집단에 서 관용구 설명하기는 SVLT_지연회상과 K-MMSE 점수와 유의한 정적 상관이 있는 것으로 나타났고 정상 노인 집단에서는 관용구 설 명하기가 SVLT_즉각회상과 유의한 정적 상관이 있는 것으로 나타났다. 인지기능 관련 변수 중에서 알츠하이머 치매 환자 집단의 관용 구 설명하기를 가장 잘 예측하는 변수는 SVLT_지연회상으로 나타났다. 논의 및 결론: 알츠하이머성 치매 환자 집단은 문자적 의미를 억제하는 능력이 저하되어 정상 노인 집단에 비해 관용구 처리 능력이 낮게 나타났다. 또한 장기기억은 알츠하이머성 치매 환자의 관용 구 설명하기 능력의 변화를 파악할 수 있는 지표가 될 수 있다는 점을 시사한다.

핵심어: 알츠하이머성 치매, 관용구, 장기기억

본 연구는 2019년도 산업통상자원부 및 산업기술평가관리원(KEIT) 연구비 지원에 의한 연구임('10077553').

\section{참고문헌}

강연욱(2006). K-MMSE(Korean-mini mental state examination)의 노인 규준 연구. 한국심리학회지, 25(2), 1-12.

강연욱, 나덕렬(2003). 서울신경심리검사(Seoul Neuropsychological Screening Battery; SNSB). 서울: 휴브알엔씨.

강연욱, 장승민, 나덕렬(2012). 서울신경심리검사 2판(Seoul Neuropsychological Screening Battery, SNSB-II). 서울: 휴브알엔씨.

고은(2018). 알츠하이머 치매 노인의 화용언어 능력. 한국청각.언어장애교육연구, 9(1), 63-78.

김지혜, 윤지혜(2016). 정상 청년층과 노년층의 비유언어 이해 능력: 직유, 은유, 관용어, 속담을 중심으로. 한국노년학, 36(4), 981-1001.

대한신경정신의학회(2002). 치매. 서울: 조선일보사.

문금현(2002). 한국어 어휘 교육을 위한 연어(連語) 학습 방안. 국어교육, 109(0), 217-250.

보건복지부, 중앙치매센터(2019). 치매대응전략 국제 학술대회 발표 자료집. 서울: 보건복지부.

서울대(1973). 동아문화 연구소 편. 국어 국문학사전. 서울: 신구 문화사.

우희림, 김향희, 김정완(2015). 실행장애 예측 지표로서 속담이해 과제의 유용성. 한국노년학, 35(3), 785-796.

장해숙, 최현주(2010). 우뇌 손상 환자의 간접화행 이해 능력. 언어청각장애연구, 15(4), 581-591.

정승은(2008). 뇌손상 환자의 관용구 이해능력. 이화여자대학교 대학원 석사학위논문.

조재윤(1988). 국어 속담의 문법구조연구. 고려대학교 대학원 박사학위논문.

최운실(1990). 한국의 문해 실태와 문해교육 (RR90-14). [KEDI] 연구보고서, 1-229.

통계청(2018). 고령화 통계. 대전: 통계청.

\section{ORCID}

전선경(제1저자, 대학원생 https://orcid.org/0000-0001-7693-0069); 성지은(교신저자, 교수 https://orcid.org/0000-0002-1734-0058) 